\begin{tabular}{|c|c|c|}
\hline \multirow{3}{*}{$\begin{array}{r}\text { Case Reports in } \\
\text { Gastroenterology }\end{array}$} & \multirow{2}{*}{\multicolumn{2}{|c|}{ Case Rep Gastroenterol 2019;13:178-184 }} \\
\hline & & \\
\hline & $\begin{array}{l}\text { DOI: 10.1159/000499445 } \\
\text { Published online: April 9, } 2019\end{array}$ & $\begin{array}{l}\text { (c) } 2019 \text { The Author(s) } \\
\text { Published by S. Karger AG, Basel } \\
\text { www.karger.com/crg }\end{array}$ \\
\hline & $\begin{array}{l}\text { This article is licensed under } \\
\text { International License (CC BY-N } \\
\text { Usage and distribution for comm }\end{array}$ & $\begin{array}{l}\text { mons Attribution-NonCommercial } 4.0 \\
\text { ger.com/Services/OpenAccessLicense). } \\
\text { uires written permission. }\end{array}$ \\
\hline
\end{tabular}

\title{
Osteopathic Manipulative Treatment in a Paediatric Patient with Oesophageal Atresia and Tracheo-Oesophageal Fistula
}

\author{
Alice Barni ${ }^{a} \quad$ Dario Zecchillo ${ }^{b} \quad$ Stefano Uberti ${ }^{b} \quad$ Silvia Ratti ${ }^{b}$ \\ aDepartment of Cranial Osteopathy, Istituto Superiore di Osteopatia (ISO), Milan, Italy; \\ ${ }^{b}$ Research Department, Istituto Superiore di Osteopatia (ISO), Milan, Italy
}

\section{Keywords}

Osteopathic manipulative treatment - Oesophageal atresia - Tracheo-oesophageal fistula . Paediatric Eating Assessment Tool-10 · Deglutition disorders

\begin{abstract}
This study is aimed to evaluate the effectiveness of osteopathic manipulative treatment (OMT) in dysphagia symptoms and aspiration risk. This is a clinical case report on a 40-day-old infant with a diagnosis of oesophageal atresia and tracheo-oesophageal fistula. The patient received one OMT every 15 days for 7 times. The clinical outcome was the clinical changes in dysphagia symptoms assessed by the Paediatric Eating Assessment Tool-10 (PEDI-EAT-10). At the first osteopathic evaluation (T0), the total score of the PEDI-EAT-10 was 7, at the fourth osteopathic evaluation (T1), the total score was 3, and at the seventh osteopathic evaluation (T2), the total score was 1. OMT was effective and safe in reducing dysphagia symptoms and aspiration risk.

(c) 2019 The Author(s)
\end{abstract}

Published by S. Karger AG, Basel 


\section{Introduction}

Oesophageal atresia (OA) with distal or proximal tracheo-oesophageal fistula (TOF) is a congenital malformation of the continuity of the oesophageal lumen with abnormal communication between the oesophagus and trachea [1]. The incidence is around 1:2,400/4,500 newborns [2].

The thoracoscopic technique is the current gold standard intervention to correct OA/TOF, with a survival rate of at least $90 \%$ [3]. Despite the effectiveness of this surgical procedure [4], there are lifelong clinical complications [5-7], such as recurrent respiratory infections, musculoskeletal asymmetry, neurodevelopmental delay, anastomotic stricture, gastro-oesophageal reflux disorders, oesophagitis and Barrett's oesophagus, swallowing difficulties, tracheomalacia, and dysphagia $[3,8]$.

OA, with or without TOF, can be diagnosed as an isolated malformation or as a part of a polymalformative syndrome with possible vertebral anomalies [9]. Several studies have shown that OA/TOF patients have a higher risk of scoliosis [10]. Operative techniques for the initial OA/TOF repair [11], as well as the presence of vertebral malformations, may lead to the development of scoliosis, but their respective role is still unclear.

Feeding problems, which occur in $79 \%$ of infants [12], increase the risk of airway aspiration and might be responsible for chronic respiratory morbidity, such as recurrent pneumonia, asthma, and bronchiolitis [13].

A body of evidence underlined the lack of a systematic treatment of nutritional complications related with OA/TOF [2] and the need for a multidisciplinary approach [14, 15]. A recent study drafted a rehabilitation protocol on swallowing function, including hyolaryngeal mobilization [16], which is a specific manual approach [17].

Osteopathic manipulative treatment (OMT) is described by the National Institutes of Health as a complementary and alternative medicine that involves a manual approach for the evaluation and treatment. OMT is aimed to improve the functionality of the skeletal, arthrodial, visceral and myofascial structures and their related vascular, lymphatic and neural elements altered by somatic dysfunctions (ICD-10-CM diagnosis code M99.00-09) [18, 19]. Moreover, a recent systematic review described OMT as a safe procedure for infants because of the absence of adverse events [20].

There is no evidence about the role of OMT in the treatment of infants with OA/TOF, only a review shows the effectiveness of OMT in the treatment of feeding dysfunctions [21].

This case report describes the effectiveness of OMT on dysphagia symptoms in a newborn with OA/TOF.

\section{Case Report}

The patient underwent the first osteopathic consultation 40 days after birth at the Centro di Medicina Osteopatica (Milan, Italy). His mother reported great difficulties in bottle-feeding, like choking when eating and vomiting after feeding, despite maintaining a standing position for at least $30 \mathrm{~min}$, as suggested when the baby was discharged by the hospital. The infant was also described by his parents as often irritable with worsening barking cough and expiratory stridor, struggling to fall asleep.

The patient was a male 40-day-old Caucasian infant with a diagnosis of OA with distal TOF; type C Gross classification [8]. 
He was born in the 40th week (eutocic labour) with a birth weight of 3,310 g, and his APGAR score was $9 / 10$ both at the 1 st and 5 th min. Six hours after birth the infant manifested respiratory distress, therefore he underwent 3 chest X-ray examinations, bronchoscopy, physical examination, and echocardiography. Moreover, the abdominal ultrasonography revealed a solitary kidney and mild tracheomalacia.

His mother was a 38-year-old Caucasian woman pregnant for the third time, not exposed to smoke or alcohol [22], with no history of genetic/congenital disorders [23]; his father was a 44-year-old Caucasian man with no genetic disorders [24].

Thoracoscopic surgery and the ligation of TOF were carried out on day 2 . The patient started being fed at the 20th day and was discharged at the 30th day after birth with a daily dosage of $8 \mathrm{mg}$ omeprazole. The gastroenterologist gave some feeding advice, such as the positioning during feeding and an infant-specific formula for reflux.

According to guidelines from the International Network of Oesophageal Atresia [2], three monthly endoscopies were scheduled for the evaluation and treatment of anastomotic stricture. Dilation with a pneumatic balloon occurred twice, in the 3rd and 6th month after birth, achieving an oesophageal diameter of $14 \mathrm{~mm}$.

The osteopathic evaluation was carried out by an osteopath with more than 10 years of paediatric clinical experience. It revealed diaphragmatic movement restriction, chest and rib stiffness, right-bending of the trunk, hypomobility of the tracheal cartilages and hyoid bone in elevation, while the normal range of motion was preserved for what concerns the shoulder girdles. A somatic dysfunction was found at the cervical spinal segment. The cranial rhythmic impulse was ranked as a low rate (4 cycles per min; cpm) and the underlying cranial strain dysfunction was a compression $[25,26]$. The patient underwent one OMT every 15 days for 7 times.

More specifically, since the clear presence of a cervical somatic dysfunction, the sequence of osteopathic treatments was mainly addressed to improve the movement of the ribs, the diaphragm, and cervical structures, such as the tracheal cartilages and the supra- and infrahyoid muscles [17, 27]. In accordance with the osteopathic scientific literature in the paediatric field $[27,28]$, fascial release, balanced ligamentous/membranous tension, indirect fluidic techniques, V-spread and specific visceral assessment and techniques were included in the osteopathic sessions, in relation to the found palpatory findings.

The dysphagia symptoms were evaluated at the first treatment (T0), at the 4th treatment (T1), and finally at the 7th treatment (T2) by the Paediatric Version of the Eating Assessment Tool-10 (PEDI-EAT-10) in Italian (Fig. 1) [29].

This clinical self-administered questionnaire is characterized by 10 items designed to predict the risk of aspiration in children with OA. Respondents specify their level of impairment on a 5-point scale ranging from no difficulty ( 0 points) to severe difficulty ( 4 points). A total score (calculated as the sum of all the answers) of 3 or more is abnormal [30, 31].

In order to assess the effectiveness of OMT, the PEDI-EAT-10 was considered as suitable to study clinical changes in dysphagia symptoms [31].

At the first visit (T0), the PEDI-EAT-10 total score was 7. More specifically, the patient scored 1 point for item 1 ("my child does not gain weight due to his/her swallowing problem") and item 3 ("swallowing liquids takes extra effort for my child"), 2 points for item 2 ("swallowing problem of my child interferes with our ability to go out for meals"), and 3 points for item 8 ("food sticks in my child's throat and my child chokes while eating") (Fig. 2).

At T1, the total score was 3: items 2 and 3 decreased to 0 , item 8 decreased to 2 , but no changes were recorded for what concerns item 1 . 
At T2, the total score was 1: all the items were equal to 0 except for item 1 , which showed no difference for the whole trial. At the same time, the cervical somatic dysfunction found during the first visit was completely normalized, and the patient's cranial rhythmic impulse was ranked as a normal rate $(9 \mathrm{cpm})$. The patient showed no adverse events in relation to OMT.

\section{Discussion}

The results of the PEDI-EAT-10 suggested the effectiveness of OMT in reducing dysphagia symptoms and the aspiration risk in a 40-day-old infant with a diagnosis of oesophageal atresia and TOF repair after thoracoscopic surgery. In fact, at the end of the study, the total score of the PEDI-EAT-10 was above the cut-off of 3 , which is considered as no risk of aspiration [31].

In accordance with neurological evidence, the osteopathic fascial manipulation seems to stimulate the intra-facial mechanoreceptors (Golgi, Pacini, Ruffini and interstitial ones), which are strongly linked to the autonomic nervous system. More specifically, fascial manipulation can generate a proprioceptive input to the central nervous system, thus influencing the tonus of related skeletal motor units and releasing hypertonic tissues [32]. Depending on the effect of the osteopath's touch, millions of motor units can be recruited. Furthermore, the stimulation of interstitial receptors and Ruffini endings could affect the autonomic nervous system, by lowering the sympathetic tonus, changing the local vasodilation and changing the fascial pre-tension, regulated by the smooth muscle cells surrounding fascia [33].

In addition, thanks to some in vitro studies, it is possible to hypothesize that OMT could have an effect on supporting the tissues surgically treated by thoracoscopic procedures. In fact, since the importance of fibrogenesis in the wound healing process, fascial release was suggested to produce an effect on remodelling of fibroblast morphology and physiology [3436]. This thesis is consistent with the need of conservative approaches in treating clinical complications following the OA/TOF surgical repair [7]. Therefore, fascial release [27] and hyoid bone mobilization $[16,17]$ might have improved the impaired cervical fascial sliding and rib mobility, biomechanically supporting the diaphragmatic respiratory dynamics [37] and cervical spine [38], thus resolving the cervical somatic dysfunction [39, 40].

Moreover, it is possible to hypothesize that OMT could have a positive role for what concerns the prevention of OA/TOF-related symptoms, such as gastro-oesophageal reflux disorders and relative respiratory infections [41], resulting in negative effects on their quality of life [42-44].

The limitations of this study include the short-term protocol planned for this patient. Indeed, a proper schedule of many long-term follow-ups would have better supported our knowledge of OA/TOF prognosis in relation to OMT. Therefore, further studies are recommended to support the effectiveness of OMT and its integration into a long-term multidisciplinary approach to paediatric patients with OA/TOF.

Similarly to other studies in the osteopathic paediatric field [45], this clinical trial supported OMT as a safe therapeutic strategy, because the patient reported no OMT-related adverse events.

In conclusion, OMT seems to be effective in reducing dysphagia symptoms and aspiration risk in a short-term period. To the authors' knowledge, this is the first clinical trial aimed to study the effectiveness of OMT in reducing dysphagia symptoms and aspiration risk. 


\section{Acknowledgement}

We thank the parents of the child described for allowing us to share his details and thank Dr. Viviana Pisa for critical reviewing the manuscript and Dr. Elena Cerasetti for revising the language.

\section{Statement of Ethic}

This case report was conducted at the Centro di Medicina Osteopatica (CMO), Istituto Superiore di Osteopatia (ISO) in Milan, Italy. All the study procedures were approved by a board of ISO experts, according to the Declaration of Helsinki's standards and the guidelines for good clinical practice. The patient's mother gave written informed consent to publish the case.

\section{Disclosure Statement}

The authors have no conflicts of interest to declare.

\section{Author Contribution}

A.B. conceived the present idea and performed the treatment. All authors wrote the manuscript and provided critical feedback and helped shape the research, analysis and the manuscript.

\section{References}

1 Duvoisin G, Krishnan U. Gastric Function in Children with Oesophageal Atresia and Tracheoesophageal Fistula. Front Pediatr. 2017 Apr;5:76.

2 Krishnan U, Mousa H, Dall'Oglio L, Homaira N, Rosen R, Faure C, et al. ESPGHAN-NASPGHAN guidelines for the evaluation and treatment of gastrointestinal and nutritional complications in children with esophageal atresiatracheoesophageal fistula. J Pediatr Gastroenterol Nutr. 2016 Nov;63(5):550-70.

3 Roberts K, Karpelowsky J, Fitzgerald DA, Soundappan SS. Outcomes of oesophageal atresia and tracheooesophageal fistula repair. J Paediatr Child Health. 2016 Jul;52(7):694-8.

4 Fonte J, Barroso C, Lamas-Pinheiro R, Silva AR, Correia-Pinto J. Anatomic Thoracoscopic Repair of Esophageal Atresia. Front Pediatr. 2017 Jan;4:142.

5 Rintala RJ, Pakarinen MP. Long-term outcome of esophageal anastomosis. Eur J Pediatr Surg. 2013 Jun;23(3): 219-25.

6 Holcomb GW 3rd. Thoracoscopic surgery for esophageal atresia. Pediatr Surg Int. 2017 Apr;33(4):475-81.

7 Tambucci R, Angelino G, De Angelis P, Torroni F, Caldaro T, Balassone V, et al. Anastomotic Strictures after Esophageal Atresia Repair: Incidence, Investigations, and Management, Including Treatment of Refractory and Recurrent Strictures. Front Pediatr. 2017 May;5:120.

8 Friedmacher F, Kroneis B, Huber-Zeyringer A, Schober P, Till H, Sauer H, et al. Postoperative Complications and Functional Outcome after Esophageal Atresia Repair: Results from Longitudinal Single-Center Follow-Up. J Gastrointest Surg. 2017 Jun;21(6):927-35.

9 Keckler SJ, St Peter SD, Valusek PA, Tsao K, Snyder CL, Holcomb GW 3rd, et al. VACTERL anomalies in patients with esophageal atresia: an updated delineation of the spectrum and review of the literature. Pediatr Surg Int. 2007 Apr;23(4):309-13.

10 Bastard F, Bonnard A, Rousseau V, Gelas T, Michaud L, Irtan S, et al. Thoracic skeletal anomalies following surgical treatment of esophageal atresia. Lessons from a national cohort. J Pediatr Surg. 2018 Apr;53(4):605-9.

11 Dunlay RP, Jones KB, Weinstein SL. Scoliosis caused by rib fusion following thoracotomy for tracheoesophageal fistula: case report. Iowa Orthop J. 2007;27:95-8. 


\section{Case Reports in Gastroenterology}

Case Rep Gastroenterol 2019;13:178-184

DOI: $10.1159 / 000499445$

(c) 2019 The Author(s). Published by S. Karger AG, Basel www.karger.com/crg

Barni et al: Osteopathic Manipulative Treatment in a Paediatric Patient with Oesophageal Atresia and Tracheo-Oesophageal Fistula

12 Mahoney L, Rosen R. Feeding Problems and Their Underlying Mechanisms in the Esophageal AtresiaTracheoesophageal Fistula Patient. Front Pediatr. 2017 May;5:127.

13 Kovesi T. Aspiration Risk and Respiratory Complications in Patients with Esophageal Atresia. Front Pediatr. 2017 Apr;5:62.

14 Giudici LB, Bokser VS, Golombek SG, Castrillon CC, Trovato M, Ferrario CC. Esophageal atresia: long-term interdisciplinary follow-up. J Pediatr Neonatal Individ Med. 2016;5(2):1-8.

15 IJsselstijn H, Gischler SJ, Toussaint L, Spoel M, Zijp MH, Tibboel D. Growth and development after oesophageal atresia surgery: need for long-term multidisciplinary follow-up. Paediatr Respir Rev. 2016 Jun;19:34-8.

16 Serel Arslan S, Soyer T, Demir N, Yalcın S, Karaduman A, Karnak I, et al. Effect of Swallowing Rehabilitation Protocol on Swallowing Function in Patients with Esophageal Atresia and/or Tracheoesophageal Fistula. Eur J Pediatr Surg. 2017 Dec;27(6):526-32.

17 Marszałek S, Niebudek-Bogusz E, Woźnicka E, Malińska J, Golusiński W, Śliwińska-Kowalska M. Assessment of the influence of osteopathic myofascial techniques on normalization of the vocal tract functions in patients with occupational dysphonia. Int J Occup Med Environ Health. 2012 Jun;25(3):225-35.

18 World Health Organization. Benchmarks for training in traditional/complementary and alternative medicine: Benchmarks for Training in Osteopathy [Internet]. World Health Organization. 2010. p. 1-23. Available from: http://www.who.int/medicines/areas/traditional/BenchmarksforTraininginOsteopathy.pdf.

19 Educational Council on Osteopathic Principles. Glossary of osteopathic terminology. In: American Association of Colleges of Osteopathic Medicine, editor. Foundations for Osteopathic Medicine. Bethesda, MD: American Association of Colleges of Osteopathic Medicine; 2011. p. 1229-53.

20 Lanaro D, Ruffini N, Manzotti A, Lista G. Osteopathic manipulative treatment showed reduction of length of stay and costs in preterm infants: A systematic review and meta-analysis. Medicine (Baltimore). 2017 Mar;96(12):e6408.

21 Cornall D. A review of the breastfeeding literature relevant to osteopathic practice. Int J Osteopath Med. 2011;14(2):61-6.

22 Wong-Gibbons DL, Romitti PA, Sun L, Moore CA, Reefhuis J, Bell EM, et al. Maternal periconceptional exposure to cigarette smoking and alcohol and esophageal atresia +/- tracheo-esophageal fistula. Birth Defects Res A Clin Mol Teratol. 2008 Nov;82(11):776-84.

23 Brunner HG, van Bokhoven H. Genetic players in esophageal atresia and tracheoesophageal fistula. Curr Opin Genet Dev. 2005 Jun;15(3):341-7.

24 Shaw-Smith C. Oesophageal atresia, tracheo-oesophageal fistula, and the VACTERL association: review of genetics and epidemiology. J Med Genet. 2006 Jul;43(7):545-54.

25 Ferguson A. A review of the physiology of cranial osteopathy. J Osteopath Med. 2003;6(2):74-84.

26 Halma KD, Degenhardt BF, Snider KT, Johnson JC, Flaim MS, Bradshaw D. Intraobserver reliability of cranial strain patterns as evaluated by osteopathic physicians: a pilot study. J Am Osteopath Assoc. 2008 Sep;108(9):493-502.

27 Cerritelli F, Martelli M, Renzetti C, Pizzolorusso G, Cozzolino V, Barlafante G. Introducing an osteopathic approach into neonatology ward: the NE-O model. Chiropr Man Therap. 2014 May;22(1):18.

28 Cerritelli F, Pizzolorusso G, Ciardelli F, La Mola E, Cozzolino V, Renzetti C, et al. Effect of osteopathic manipulative treatment on length of stay in a population of preterm infants: a randomized controlled trial. BMC Pediatr. 2013 Apr;13(1):65.

29 Schindler A, Mozzanica F, Monzani A, Ceriani E, Atac M, Jukic-Peladic N, et al. Reliability and validity of the italian eating assessment tool. Ann Otol Rhinol Laryngol. 2013 Nov;122(11):717-24.

30 Möller R, Safa S, Östberg P. Validation of the Swedish translation of eating assessment tool (S-EAT-10). Acta Otolaryngol. 2016 Jul;136(7):749-53.

31 Soyer T, Yalcin S, Arslan SS, Demir N, Tanyel FC. Pediatric Eating Assessment Tool-10 as an indicator to predict aspiration in children with esophageal atresia. J Pediatr Surg. 2017 Oct;52(10):1576-9.

32 Tunnell PW. Muscle length assessment of tightness-prone muscles. J Bodyw Mov Ther. 1998;2(1):21-7.

33 Schleip R. Fascial plasticity - a new neurobiological explanation: Part 1. J Bodyw Mov Ther. 2003;7(1):11-9.

34 Zein-Hammoud M, Standley PR. Modeled Osteopathic Manipulative Treatments: A Review of Their in Vitro Effects on Fibroblast Tissue Preparations. J Am Osteopath Assoc. 2015 Aug;115(8):490-502.

$35 \mathrm{Ng} \mathrm{CP}$, Hinz B, Swartz MA. Interstitial fluid flow induces myofibroblast differentiation and collagen alignment in vitro. J Cell Sci. 2005 Oct;118(Pt 20):4731-9.

36 Langevin HM, Nedergaard M, Howe AK. Cellular control of connective tissue matrix tension. J Cell Biochem. 2013 Aug;114(8):1714-9.

37 Courtney R. The functions of breathing and its dysfunctions and their relationship to breathing therapy. Int J Osteopath Med. 2009;12(3):78-85.

38 Tozzi P, Bongiorno D, Vitturini C. Fascial release effects on patients with non-specific cervical or lumbar pain. J Bodyw Mov Ther. 2011 Oct;15(4):405-16.

39 Tozzi P. Selected fascial aspects of osteopathic practice. J Bodyw Mov Ther. 2012 Oct;16(4):503-19.

40 Tozzi P. A unifying neuro-fasciagenic model of somatic dysfunction - Underlying mechanisms and treatment - Part II. J Bodyw Mov Ther. 2015 Jul;19(3):526-43.

41 Faure C, Righini Grunder F. Dysmotility in Esophageal Atresia: Pathophysiology, Characterization, and Treatment. Front Pediatr. 2017 May;5:130. 


\section{Case Reports in \\ Gastroenterology}

\begin{tabular}{l|l}
\hline Case Rep Gastroenterol 2019;13:178-184 \\
\hline DOI: 10.1159/000499445 & $\begin{array}{l}\text { ( ) 2019 The Author(s). Published by S. Karger AG, Basel } \\
\text { www.karger.com/crg }\end{array}$ \\
\hline
\end{tabular}

Barni et al.: Osteopathic Manipulative Treatment in a Paediatric Patient with Oesophageal Atresia and Tracheo-Oesophageal Fistula

42 Koivusalo A, Pakarinen MP, Turunen P, Saarikoski H, Lindahl H, Rintala RJ. Health-related quality of life in adult patients with esophageal atresia - a questionnaire study. J Pediatr Surg. 2005 Feb;40(2):307-12.

43 Deurloo JA, Ekkelkamp S, Hartman EE, Sprangers MA, Aronson DC. Quality of life in adult survivors of correction of esophageal atresia. Arch Surg. 2005 Oct;140(10):976-80.

44 Maynard S, Bouin M. Follow-up of adult patients with repaired esophageal atresia: how, when, and for how long? Dis Esophagus. 2013 May-Jun;26(4):422-4.

45 Posadzki P, Lee MS, Ernst E. Osteopathic manipulative treatment for pediatric conditions: a systematic review. Pediatrics. 2013 Jul;132(1):140-52.

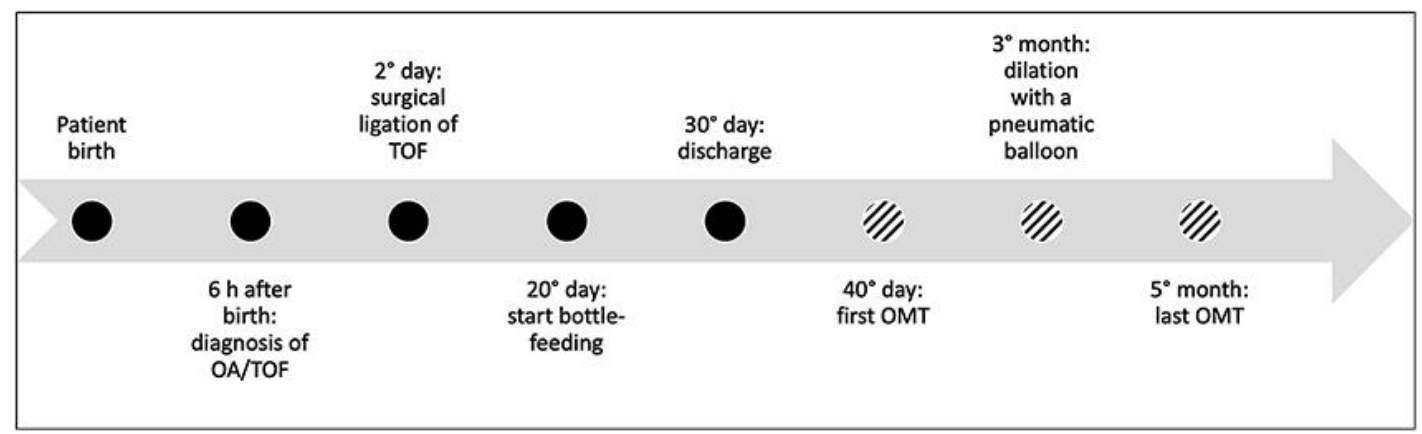

Fig. 1. Patient timeline.

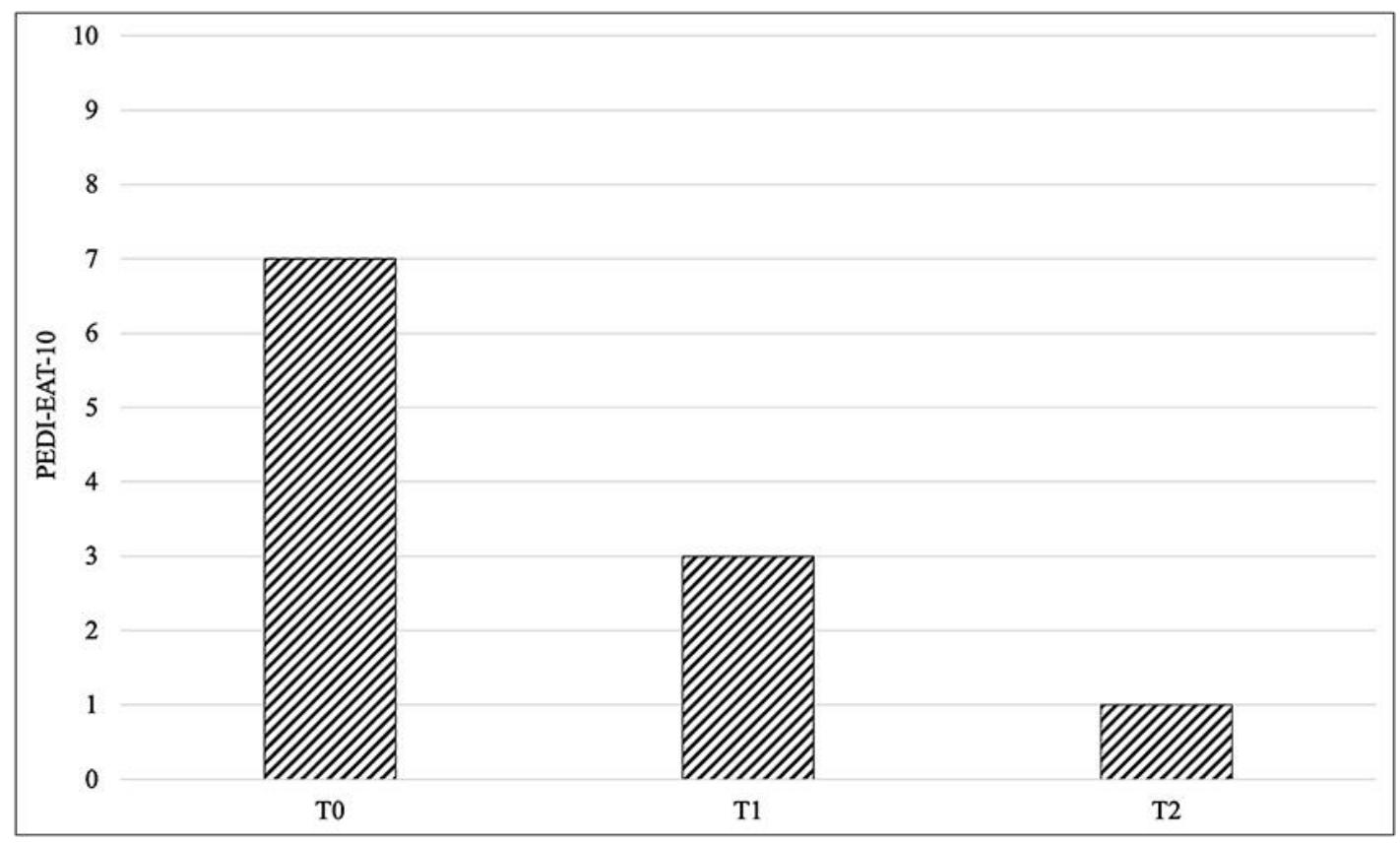

Fig. 2. PEDI-EAT-10 results (T0: 1st osteopathic visit; T1: 4th osteopathic visit; T2: 7th osteopathic visit). 